\title{
Prognostic Factors and Treatment Outcomes of Adult Patients With Rhabdomyosarcoma After Multimodality Treatment
}

\author{
YEN-TING LIU ${ }^{1}$, CHUN-WEI WANG ${ }^{1,2}$, RUEY-LONG HONG $^{3}$ and SUNG-HSIN KUO ${ }^{1,2,4,5}$ \\ ${ }^{1}$ Division of Radiation Oncology, Department of Oncology, National Taiwan University \\ Hospital and National Taiwan University College of Medicine, Taipei, Taiwan, R.O.C.; \\ ${ }^{2}$ Cancer Research Center, National Taiwan University College of Medicine, Taipei, Taiwan, R.O.C.; \\ ${ }^{3}$ Division of Medical Oncology, Department of Oncology, National Taiwan University Hospital \\ and National Taiwan University College of Medicine, Taipei, Taiwan, R.O.C.; \\ ${ }^{4}$ Graduate Institute of Oncology, National Taiwan University College of Medicine, Taipei, Taiwan, R.O.C.; \\ ${ }^{5}$ National Taiwan University Cancer Center, National Taiwan University College of Medicine, Taipei, Taiwan, R.O.C.
}

\begin{abstract}
Background: Adults with rhabdomyosarcoma (RMS) have a worse clinical outcome compared to pediatric cases. In the present study, the failure pattern and clinical outcome of adult patients with RMS who received multimodality treatment at our Institution was assessed. Patients and Methods: Data were retrospectively recorded and analyzed from 20 adult patients, aged 19 years or more, who were treated for RMS at our Institution between 2004 and 2015. Disease-free (DFS) and overall (OS) survival after starting treatment were calculated using the Kaplan-Meier method. The relationship of these outcome measures with the following variables was then assessed: Primary site, tumor stage, lymph node involvement, histological subtype, radiotherapy $(R T)$, and duration of chemotherapy. Results: Sixteen patients had localized RMS, and four had metastatic disease. For the whole patient cohort, the 3-year DFS and OS rates were $20 \%$, and $45 \%$, respectively. Patients with alveolar histological subtype had a better 3-year OS than those with other subtypes $(p=0.038)$. The median OS rates for those with localized and metastatic disease were $53.2(95 \%$ confidence interval $(C I)=14.7-91.8)$ months, and $21.7(95 \%$ $C I=0-45.7)$ months, respectively ( $p=0.047)$. In patients with localized RMS, those who received $R T(n=13)$ had a better median DFS (24.6 versus 6.0 months, $p=0.009)$ and $O S(53.2$ versus 11.4 months, $p=0.009)$ than those who did not $(n=3)$.
\end{abstract}

Correspondence to: Sung-Hsin Kuo, MD, Ph.D., Division of Radiation Oncology, Department of Oncology, National Taiwan University Hospital, No. 7, Chung-Shan South Rd, Taipei, Taiwan, R.O.C. Tel: +886 223123456, ext. 67144, Fax: +886 223711174, e-mail: shkuo101@ntu.edu.tw

Key Words: Rhabdomyosarcoma, prognosis, failure pattern, radiotherapy, chemotherapy.
For patients receiving $R T$, concurrent chemotherapy with vincristine and cyclophosphamide $(n=11)$ was associated with better 3-year DFS (36.4\% versus $0 \%, p<0.001)$ and $O S$ ( $81.8 \%$ versus $0 \%, p<0.001)$ compared with $R T$ alone $(n=2)$. Administration of chemotherapy for more than 19 weeks significantly correlated with better 3-year DFS (44\% versus $0 \%, p=0.001)$ and $O S(53.3 \%$ versus $0 \%, p<0.001)$ in those with localized RMS. Conclusion: In addition to staging and histological subtype, our results indicate that concurrent chemoradiotherapy and longer duration of chemotherapy were associated with significantly improved DFS and OS in adult patients with localized RMS.

Rhabdomyosarcoma (RMS) is the most common soft-tissue malignancy, accounting for 4-5\% of cancer cases in children (1). In Taiwan, soft-tissue sarcoma accounted for approximately $40 \%$ of all pediatric cancers diagnosed between 1996 and 2010, with RMS comprising 6\% of all pediatric soft-tissue sarcomas (2). RMS is far less common in adults (2). Although most cases occur in children younger than 10 years, adult RMS still accounted for $41 \%$ of all RMS cases in the Surveillance, Epidemiology and End Results (SEER) database between 1973 and 2005 (3). Pediatric patients with RMS are typically treated within clinical studies or by standard protocols. In the United States, the Intergroup Rhabdomyosarcoma Study Group (IRSG; now the Children's Oncology Group Soft-Tissue Sarcoma Committee) organized a series of studies incorporating multimodality treatment (chemotherapy, surgery, and radiotherapy) to treat pediatric RMS, and the 5-year overall survival (OS) after treatment clearly improved from $55 \%$ in IRS-I to over $71 \%$ in IRS-IV (4-6). However, the IRS studies enrolled only patients under 21 year of age, most of whom were under 14 years old, hence their results are not valid for adult patients with RMS (4-6). In contrast, treatment of adult 
RMS (age >19 years) is still non-standardized and depends on the experience and personal choice of different physicians. The treatment outcome of adult RMS has been demonstrated to be inferior to that of pediatric RMS $(3,7)$.

Tumor cells of RMS arise from progenitors of skeletal muscle cells throughout the body. The histology of adult RMS is much different from that of pediatric RMS, with the pleomorphic histological subtype (undifferentiated, adult spindle cell, and not otherwise specified) being most common $(8,9)$. In contrast, embryonal and alveolar RMS subtypes are most common in children $(8,9)$. The clinical presentation of RMS varies according to the site $(10,11)$. Tumors are usually detected as a painless or rapidly growing mass. Common symptoms of head and neck RMS include cranial nerve dysfunction, sinus pressure, rhinorrhea, nasal congestion, ear discharge, headache, and facial pain, whereas tumor of extremities presents as a rapidly enlarging, firm mass $(10,11)$. Tumors occurring in the retroperitoneum and mediastinum can become quite large before producing signs and symptoms $(10,11)$. The most common locations of adult RMS are the head and neck $(40 \%)$, genitourinary tract (20\%), and extremities (20\%) (4).

In the present study, we assessed the failure pattern and clinical outcome of adult patients with RMS who were treated with multimodality treatment, including surgery, chemotherapy, and radiotherapy (RT) at our Institution over a 15 -year period, starting in 2004. We also reviewed the clinical outcome of previously published reports of adult patients with RMS. From our patient data and other investigators' studies, we hope to develop an appropriate treatment strategy for improving the outcome of adult patients with RMS.

\section{Patients and Methods}

Data collection. We retrospectively analyzed registry data from our Institution's Cancer Administration and Coordination Center. This facility was founded in 1976 with the purpose of collecting, managing, and analyzing the data of all cancer patients treated in our institution. Data from patients newly diagnosed with RMS between March 2004 and March 2015 were collected and reviewed. Seventy-seven patients with RMS were initially identified. Pediatric patients (age $<19$ years), patients with Ewing sarcoma, and patients who were treated at another hospital or received no treatment were excluded. Additionally, we excluded those with insufficient data and an inadequate follow-up period. We finally included and analyzed data from 20 adult patients with RMS aged $\geq 19$ years. No patient included in the study had a secondary malignancy.

Multimodality treatment. The treatment flowchart of these 20 adult patients with RMS is shown in Figure 1. Only one out of 20 patients did not receive chemotherapy, due to rapid disease progression after surgery and RT. Thirteen patients $(65 \%)$ received a multidrug regimen, including vincristine, actinomycin D (dactinomycin), and cyclophosphamide (VAC), alternating with ifosfamide and etoposide
Table I. Intergroup Rhabdomyosarcoma Study Group surgicall pathological clinical grouping system and risk stratification of rhabdomyosarcoma.

\begin{tabular}{ll}
\hline Group & Description \\
\hline I & $\begin{array}{l}\text { Localized disease, completely resected } \\
\text { Gross total resection with } \\
\text { a. Microscopic positive margins } \\
\text { b. Regional lymph node involvement and resected } \\
\text { c. Both }\end{array}$ \\
Incomplete resection of gross disease \\
II & Metastatic disease \\
\hline Risk & Description \\
\hline Low & $\begin{array}{l}\text { Localized, embryonal subtype, any resected site } \\
\text { (Group II or III) or favorable sites Group III }\end{array}$ \\
Intermediate & $\begin{array}{l}\text { Any localized alveolar subtype (Group I-III) } \\
\text { or any unfavorable site Group III }\end{array}$ \\
High & Metastatic disease \\
\hline
\end{tabular}

(IE). During RT, the addition of concurrent chemotherapy with vincristine and cyclophosphamide (VC) was prescribed in 10 patients (Figure 1). Two patients received chemotherapy with doxorubicin and ifosfamide. One patient received the Taiwan Pediatric Oncology Group protocol RMS 95D (VAC and vincristine alternating with IE for 1 year plus RT) treatment (12), and another received the modified POG9354/CCG7932 protocol (mainly VAC, VC and IE) treatment (13). ARST0431 (including irinotecan) was prescribed for one patient with stage IV disease (14). One patient with a uterine RMS received cisplatin and paclitaxel prescribed by her gynecologist.

RT was delivered by a cobalt-60 machine, linear accelerator or Tomotherapy system using photon or electron beam energies with fractionated schedules of 1.8 to 2.2 Gray (Gy) daily for 5 days per week. The RT techniques included three-dimensional (3D) conformal RT, intensity-modulated radiation therapy (IMRT), and volumetric-modulated arc therapy (VMAT) planning system. Overall, 14 patients received RT, with only one for palliation. Among the 13 patients receiving RT for curative purpose, the total dose of RT ranged from 50 to $63 \mathrm{~Gy}$, with a median dose of $56 \mathrm{~Gy}$. RT fields included the initial volume of the tumor plus $2 \mathrm{~cm}$ margins, as well as any involved lymph nodes.

Statistical methods. Patient variables were stratified by age, sex, site of origin, tumor size, stage, histology, chemotherapy duration, clinical groups, and risk level. Patients were also divided into two categories, those with favorable and unfavorable sites, according to the primary tumor site. Favorable sites included the orbit, nonparameningeal head and neck, non-bladder/non-prostate genitourinary tract, and biliary tract. All other sites were considered unfavorable. Before treatment, the patients were categorized using the IRSG staging system, in which stage I to III indicates localized disease and stage IV indicates metastatic spread; patients were also categorized using the IRSG surgical/pathologic clinical grouping system (Table I) $(15,16)$. In addition, the data from IRS-III and IRSIV provided rationale for risk stratification into low-risk, intermediate-risk, and high-risk groups, which is highly predictive 


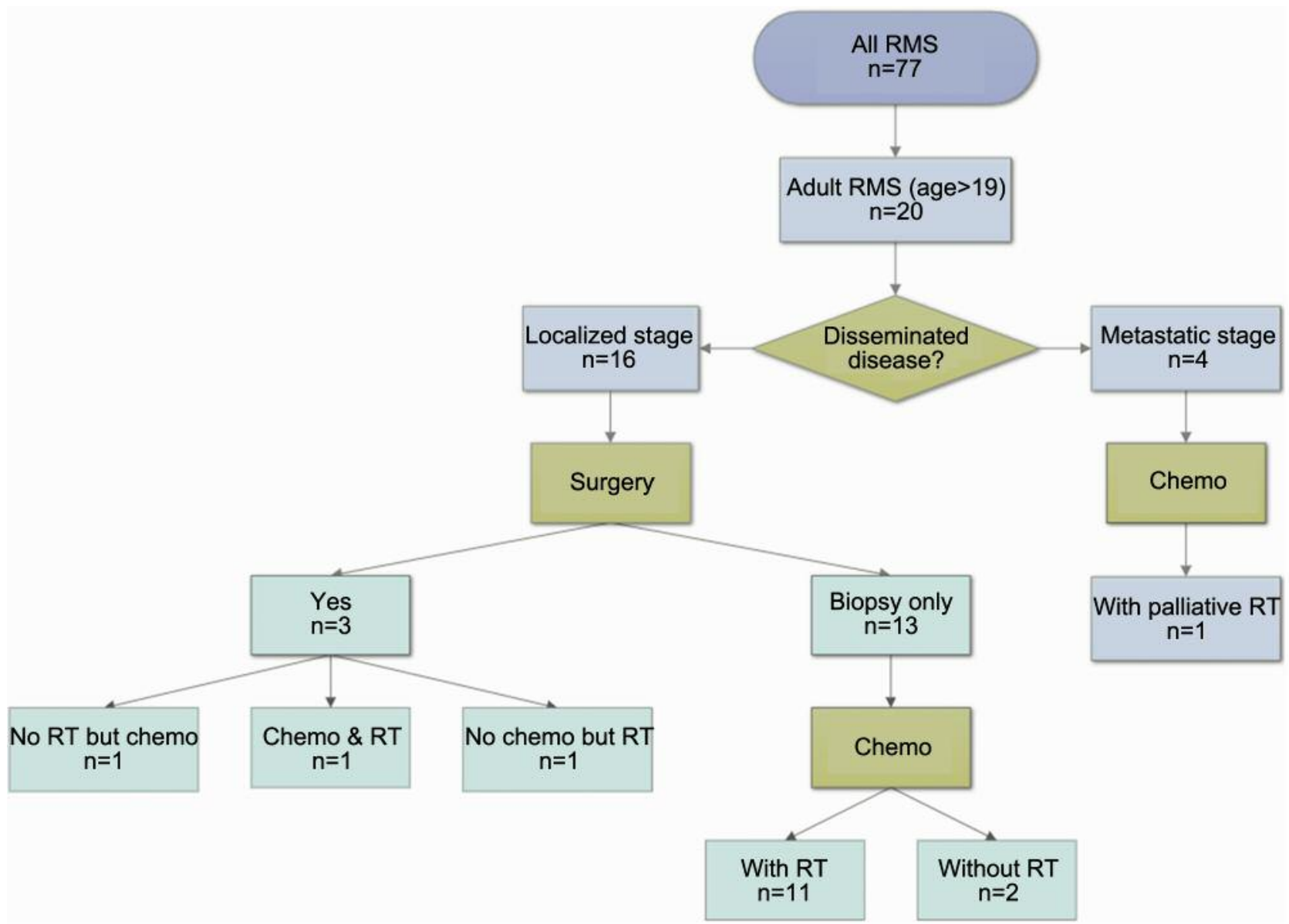

Figure 1. Treatment flowchart of total adult patients with rhabdomyosarcoma (RMS). Chemo: Chemotherapy; RT: radiotherapy.

of outcome in patients with RMS (Table I) (17-19). Disease-free survival (DFS) was measured from the date of the original surgery for RMS to the date of local or distant recurrence, or death from any cause. OS was calculated from the day of surgery or biopsy to the day of death from any cause, or the day of last follow-up. Survival was calculated according to the Kaplan-Meier method. DFS and OS curves were compared between variables using the log-rank test. All tests were two-sided with $p<0.05$ indicating significance.

\section{Results}

Clinicopathological features of adult RMS. The clinicopathological features of the 20 patients in this study are listed in Table II. Median follow-up time was 44 months, and median age at diagnosis was 34 (range $=19-79)$ years. Sixteen presented with localized disease (four stage I, four stage II, and 8 stage III disease), and four presented with metastases at initial diagnosis (two with extremities primary site and two with genitourinary primary site). Among all patients, the most frequent primary site was the head and neck (12 patients, 60\%). According to the IRSG risk stratification, most patients were at intermediate risk $(15 / 20,75 \%)$. Of the 20 patients, 14 received RT treatment for primary sites due to residual disease, whereas three patients with localized disease did not receive RT. Nineteen patients $(95 \%)$ received chemotherapy; of these, $13(55 \%)$ received chemotherapy for $>19$ weeks.

Clinical outcomes and prognostic factors in all adult RMS patients. Twelve out of the $20(60 \%)$ patients died of their disease. By tumor histology, 7/9 (77.8\%) with pleomorphic subtype, $2 / 8(25 \%)$ with alveolar subtypes, and all three embryonal cases died. For the whole patient cohort, the 3year DFS and OS rates were $20 \%$ and $45 \%$, respectively (Figure 2). The respective stage I, II, III, and IV 3-year DFS rates were $50 \%, 25 \%, 12.5 \%$ and $0 \%$; the 3 -year OS rates were $75 \%, 50 \%, 50 \%$, and $0 \%$, respectively. The median OS for those with localized and those with metastatic disease were 53.2 [95\% confidence interval $(\mathrm{CI})=14.7-91.8]$ months and $21.7(95 \% \mathrm{CI}=0-45.7)$ months, respectively $(p=0.047)$ (Figure 3). 
Table II. Patient characteristics and demographic data of adult patients with rhabdomyosarcoma $(n=20)$.

\begin{tabular}{|c|c|}
\hline Variable & Value \\
\hline \multicolumn{2}{|l|}{ Age at diagnosis, years } \\
\hline Median (range) & $34(19-79)$ \\
\hline \multicolumn{2}{|l|}{ Gender, n (\%) } \\
\hline Male & $11(55 \%)$ \\
\hline Female & $9(45 \%)$ \\
\hline \multicolumn{2}{|l|}{ Year of diagnosis, n (\%) } \\
\hline 2004-2010 & $9(45 \%)$ \\
\hline 2011-2015 & $11(55 \%)$ \\
\hline \multicolumn{2}{|l|}{ Site, n $(\%)$} \\
\hline Head \& neck & $12(60 \%)$ \\
\hline Parameningeal & 11 \\
\hline Non-parameningeal & 1 \\
\hline Genitourinary & $6(30 \%)$ \\
\hline Bladder/prostate & 2 \\
\hline Non-bladder/prostate & 4 \\
\hline Limb & $2(10 \%)$ \\
\hline \multicolumn{2}{|l|}{ Stage, n (\%) } \\
\hline Localized & $16(80 \%)$ \\
\hline Metastatic & $4(20 \%)$ \\
\hline \multicolumn{2}{|l|}{ LN involvement, n (\%) } \\
\hline No & $9(45 \%)$ \\
\hline Yes & $10(50 \%)$ \\
\hline Unknown & $1(5 \%)$ \\
\hline \multicolumn{2}{|l|}{ Size, n $(\%)$} \\
\hline$\leq 5 \mathrm{~cm}$ & $5(25 \%)$ \\
\hline$>5 \mathrm{~cm}$ & $13(65 \%)$ \\
\hline Unknown & $2(10 \%)$ \\
\hline \multicolumn{2}{|l|}{ Histology, n (\%) } \\
\hline Embryonal & $3(15 \%)$ \\
\hline Alveolar & $8(40 \%)$ \\
\hline Pleomorphic & $9(45 \%)$ \\
\hline \multicolumn{2}{|l|}{ Postsurgical group, $\mathrm{n}(\%)^{*}$} \\
\hline 2 (R1 resection or involved LNs) & $3(15 \%)$ \\
\hline 3 (Gross residuals) & $13(65 \%)$ \\
\hline 4 (Metastasis) & $4(20 \%)$ \\
\hline \multicolumn{2}{|l|}{ Risk group, $\mathrm{n}(\%)^{\#}$} \\
\hline Low & $1(5 \%)$ \\
\hline Intermediate & $15(75 \%)$ \\
\hline High & $4(20 \%)$ \\
\hline \multicolumn{2}{|l|}{ Chemotherapy duration, $\mathrm{n}(\%)$} \\
\hline None & $1(5 \%)$ \\
\hline$\leq 19$ Weeks & $6(30 \%)$ \\
\hline$>19-45$ Weeks & $11(55 \%)$ \\
\hline$>45$ Weeks & $2(10 \%)$ \\
\hline \multicolumn{2}{|l|}{ Radiotherapy, n (\%) } \\
\hline No & $6(30 \%)$ \\
\hline Yes & $14(70 \%)$ \\
\hline \multicolumn{2}{|l|}{ VC-CCRT, n (\%) } \\
\hline No & $2(14.3 \%)$ \\
\hline Yes & $12(85.7 \%)$ \\
\hline \multicolumn{2}{|l|}{ Radiation technology, n (\%) } \\
\hline 3DRT & $3(21.4 \%)$ \\
\hline IMRT/VMAT/Tomo & $11(78.6 \%)$ \\
\hline
\end{tabular}

LN: Lymph node; VC: vincristine and cyclophosphamide; CCRT: concurrent chemoradiotherapy; 3DRT: three-dimensional conformal RT; IMRT: intensity-modulated radiation therapy; VMAT: volumetricmodulated arc therapy; Tomo: tomotherapy. *According to the Intergroup Rhabdomyosarcoma Study Group $(15,16)$; \#according to the Children's Oncology Group (17-19).
The median OS for head and neck, and genitourinary primary sites was 53.2 (95\% CI=19.7-91.8) months and 6.1 (95\% CI=17.9-41.2) months, respectively $(p=0.21)$. The $3-$ year DFS and OS rates were $11.1 \%$ and $33.3 \%$, respectively, for the nine cases diagnosed before and including 2010, and were $27.3 \%$ and $54.5 \%$, respectively, for the 11 diagnosed after 2010 (DFS, $p=0.318$; OS, $p=0.296)$. High-risk patients $(\mathrm{n}=4)$ had lower 3 -year DFS ( $0 \%$ versus $26.7 \% ; p=0.616)$ and $\mathrm{OS}(0 \%$ versus $53.5 \%$; $p=0.12)$ than intermediate-risk group patients $(\mathrm{n}=15)$. The prognostic variable analysis of DFS and OS for adult patients with RMS is listed in Table III. There were no differences in DFS in terms of sex, year of diagnosis, primary site, favorable site, bulky size, lymph node involvement, stage, histology subtype, postsurgical group, and risk group (Table III). Similarly, sex, year of diagnosis, primary site, favorable site, bulky size, lymph node involvement, stage, postsurgical group, and risk group did not affect OS. However, patients with alveolar histological subtype had a better OS $(p=0.035$, Table III).

Clinical outcome of patients with localized RMS. Regarding failure patterns in 16 patients with localized RMS (stage I to III), four had local failure, three had distant metastasis, two had regional recurrences, and one had both local and distant failure. In patients with localized RMS, the 3-year DFS rates for those with pleomorphic $(\mathrm{n}=8)$, alveolar $(\mathrm{n}=6)$ and embryonal $(\mathrm{n}=2)$ subtypes were $12.5 \%, 50 \%$, and $0 \%$, respectively $(p=0.167)$. The respective 3 -year OS rates were $25 \%, 100 \%$, and $50 \%(p=0.017)$. The 3 -year DFS and OS rates were $12.5 \%$ and $37.5 \%$, respectively, for the eight patients diagnosed from 2004 up to and including 2010, and $37.5 \%$ and $75 \%$ for the eight diagnosed after 2010 (DFS, $p=0.415$; OS, $p=0.21$ ). No secondary malignancy was found during follow-up of these patients. As shown in Figure 4A, patients receiving RT $(n=13)$ had a significantly better median DFS than those without RT $(n=3)(24.6$ versus 6.0 months, $p=0.009$ ). Similarly, patients receiving RT had a significantly better median OS than those not receiving RT (53.2 versus 11.4 months, $p=0.009$ ) (Figure 4B). Among the three patients who did not receive RT, one had post-surgical group II disease, another had complete response after chemotherapy, and the other had stage I with primary uterine disease.

There were no significant differences in DFS and OS found between patients receiving 3D RT or IMRT/VMAT/ tomotherapy (Table III). Regarding chemotherapy regimens, we found that four out of five patients who received chemotherapy cycles for $\leq 19$ weeks' duration died, while seven out of nine patients who received longer chemotherapy ( $\leq 45$ weeks) were still alive. The 3 -year DFS rate was significantly better for patients who received chemotherapy for more than 19 weeks than those who received chemotherapy $\leq 19$ weeks 

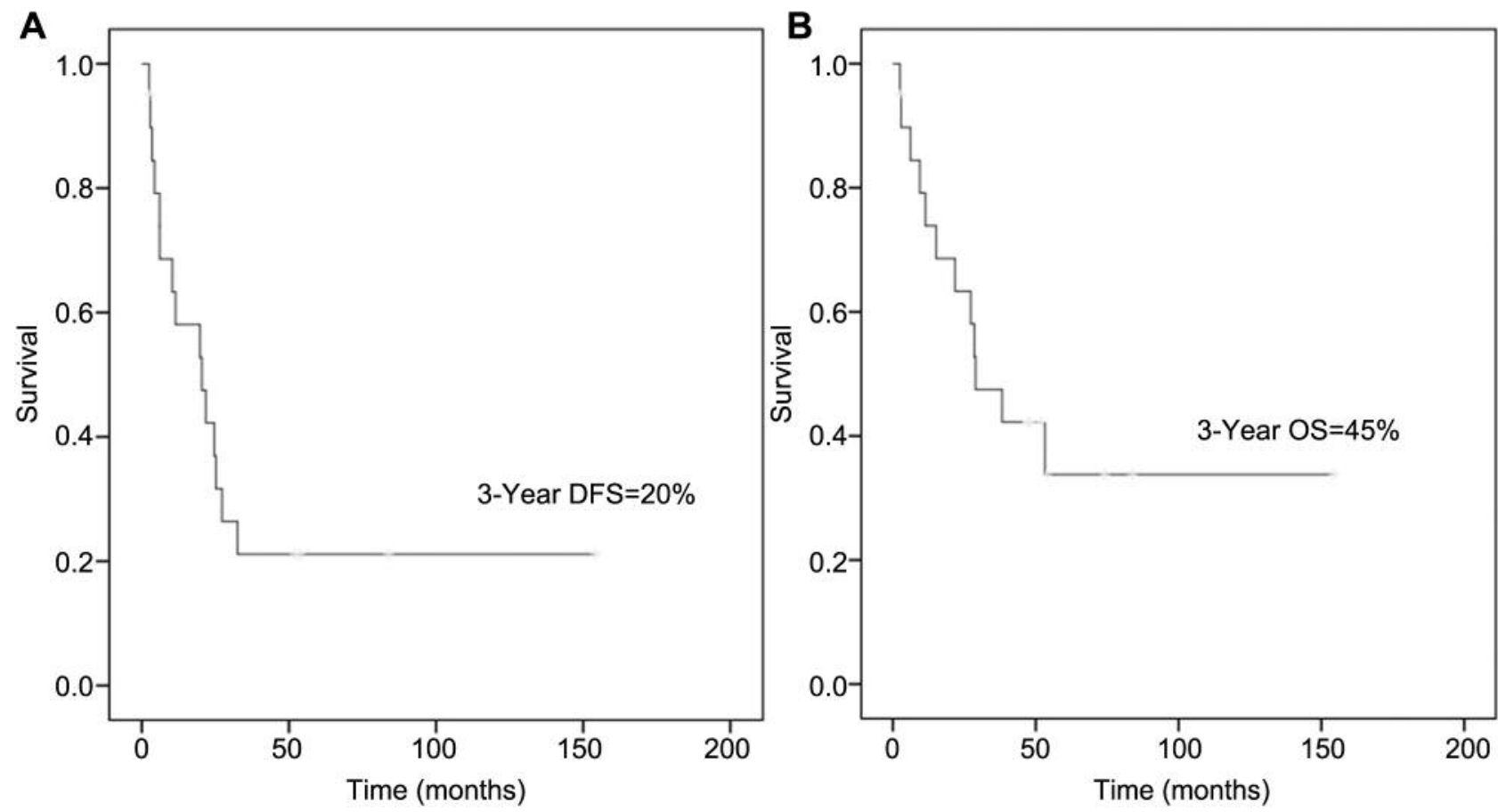

Figure 2. Disease-free survival (DFS) (A) and overall survival (OS) (B) outcomes of the whole patient cohort $(n=20)$.

A

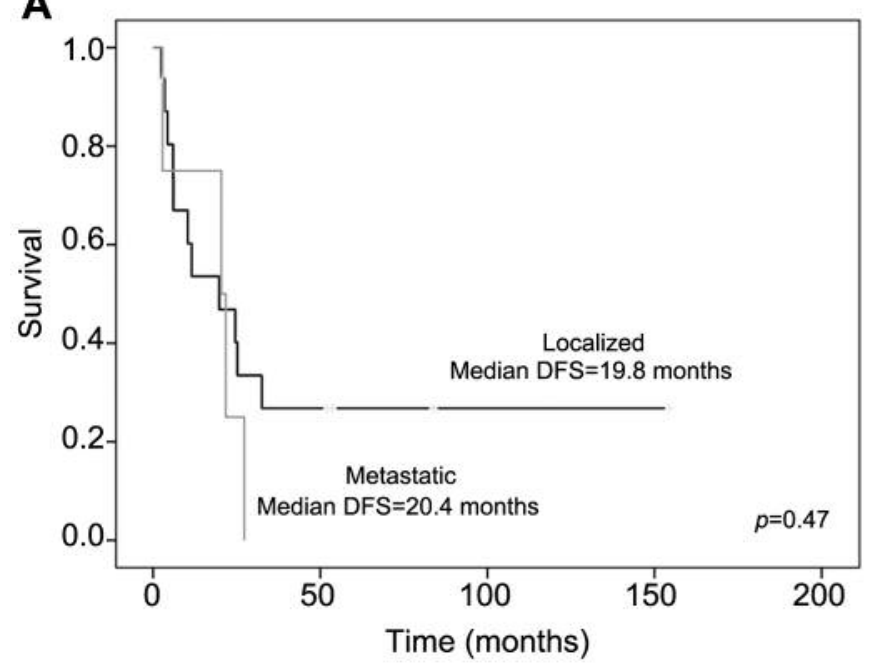

B

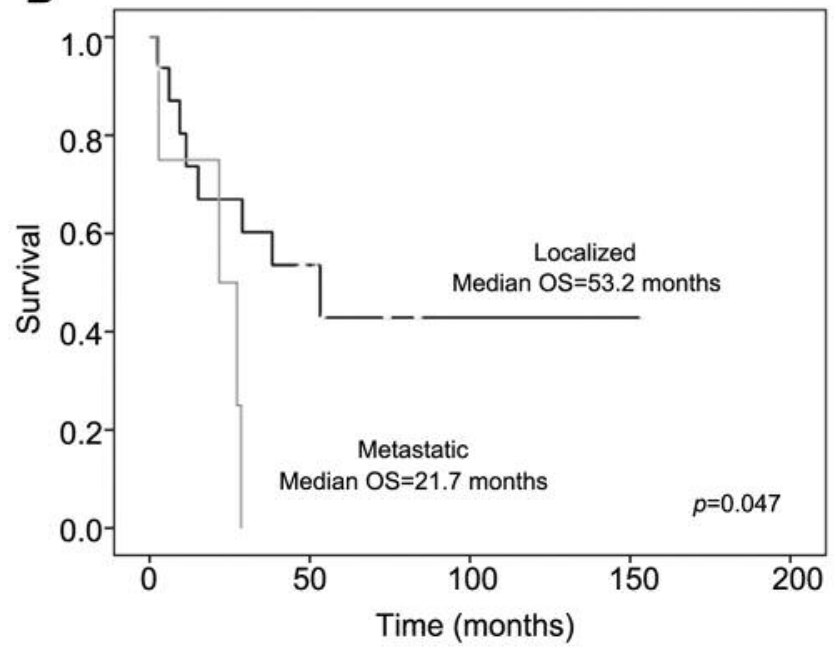

Figure 3. Disease-free survival (DFS) (A) and overall survival (OS) (B) outcomes of patients with rhabdomyosarcoma ( $n=20$ ) by stage (localized/metastatic).

(40\% versus $0 \%, p=0.009$, Figure $4 \mathrm{C}$ ). The corresponding 3year OS rates were $90 \%$ and $0 \%$ for these two groups $(p=0.009)$ (Figure 4D). When compared to those receiving RT alone, patients receiving RT concurrent with $\mathrm{VC}$ had a significantly better 3-year DFS (36.4 versus $0 \% ; p<0.01)$ and OS $(81.8 \%$ versus $0 \% ; p<0.01)$ (Table III).

\section{Discussion}

In this study, our cohort of 20 patients with adult RMS were treated with multidisciplinary treatment, including surgery, chemotherapy, or RT in the modern era. Nineteen patients received chemotherapy, with $60 \%$ of them receiving it for more 
Table III. Univariate analysis of disease-free (DFS) and overall (OS) survival.

\begin{tabular}{|c|c|c|c|c|c|c|}
\hline & Variable & Number & 3-Year DFS (\%) & $p$-Value & 3-Year OS (\%) & $p$-Value \\
\hline \multicolumn{7}{|l|}{ All patients $(n=20)$} \\
\hline \multirow[t]{2}{*}{ Gender } & Male & 11 & 18.2 & 0.798 & 45.5 & 0.862 \\
\hline & Female & 9 & 22.2 & & 44.4 & \\
\hline \multirow[t]{2}{*}{ Diagnostic year } & 2004-2010 & 9 & 11.1 & 0.318 & 33.3 & 0.296 \\
\hline & 2011-2015 & 11 & 27.3 & & 54.5 & \\
\hline \multirow[t]{8}{*}{ Tumor site } & Head \& neck & 12 & 25.0 & 0.621 & 58.3 & 0.140 \\
\hline & Non-head \& neck & 8 & 12.5 & & 25.0 & \\
\hline & Parameningeal & 11 & 18.2 & 0.219 & 54.5 & 0.450 \\
\hline & Non-parameningeal & 1 & 100 & & 100 & \\
\hline & Bladder/prostate & 2 & 0 & 0.207 & 0 & 0.207 \\
\hline & Non-bladder/prostate & 4 & 25 & & 50 & \\
\hline & Favorable site & 4 & 50 & 0.251 & 50 & 0.950 \\
\hline & Unfavorable site & 16 & 12.5 & & 43.8 & \\
\hline \multirow[t]{2}{*}{ Bulky size } & $\leq 5 \mathrm{~cm}$ & 5 & 20 & 0.771 & 40 & 0.735 \\
\hline & $>5 \mathrm{~cm}$ & 13 & 23.1 & & 46.2 & \\
\hline \multirow[t]{2}{*}{ LN Involvement } & No & 9 & 22.2 & 0.542 & 44.4 & 0.524 \\
\hline & Yes & 10 & 20 & & 50 & \\
\hline \multirow[t]{2}{*}{ Stage } & Localized & 16 & 25 & 0.574 & 56.3 & 0.089 \\
\hline & Metastatic & 4 & 0 & & 0 & \\
\hline \multirow[t]{3}{*}{ Histology } & Embryonal & 3 & 0 & 0.166 & 33.3 & 0.038 \\
\hline & Alveolar & 8 & 37.5 & & 75 & \\
\hline & Pleomorphic & 9 & 11 & & 22.5 & \\
\hline \multirow[t]{3}{*}{ Postsurgical group* } & 2 (R1 resection or involved $\mathrm{LNs}$ ) & 3 & 0 & 0.294 & 33.3 & 0.114 \\
\hline & 3 (Gross residuals) & 13 & 30.8 & & 61.5 & \\
\hline & 4 (Metastasis) & 4 & 0 & & 0 & \\
\hline \multirow[t]{3}{*}{ Risk group $\#$} & Low & 1 & 0 & 0.852 & 100 & 0.182 \\
\hline & Intermediate & 13 & 26.7 & & 53.3 & \\
\hline & High & 4 & 0 & & 0 & \\
\hline \multicolumn{7}{|l|}{ Localized disease $(n=16)$} \\
\hline \multirow[t]{2}{*}{ Diagnostic year } & 2004-2010 & 8 & 11.1 & 0.318 & 33.3 & 0.296 \\
\hline & 2011-2015 & 8 & 27.3 & & 54.5 & \\
\hline \multirow[t]{3}{*}{ Histology } & Embryonal & & 0 & 0.166 & 33.3 & 0.038 \\
\hline & Alveolar & & 37.5 & & 75 & \\
\hline & Pleomorphic & & 11 & & 22.5 & \\
\hline \multirow[t]{3}{*}{ Chemotherapy duration } & $\leq 19$ Weeks & 6 & 0 & $<0.01$ & 0 & $<0.01$ \\
\hline & $>19-45$ Weeks & 9 & 44.4 & & 53.3 & \\
\hline & $>45$ Weeks & 1 & 0 & & 100 & \\
\hline \multirow[t]{2}{*}{ Radiotherapy } & No & 3 & 0 & $<0.01$ & 0 & $<0.01$ \\
\hline & Yes & 13 & 30.8 & & 69.2 & \\
\hline \multirow[t]{2}{*}{ RT Technology } & 3DRT & 3 & 33.3 & 0.732 & 66.7 & 0.951 \\
\hline & IMRT/VMAT/Tomo & 10 & 30 & & 70 & \\
\hline \multirow{2}{*}{ Concurrent VC RT } & No & 2 & 0 & $<0.01$ & 0 & $<0.01$ \\
\hline & Yes & 11 & 36.4 & & 81.8 & \\
\hline
\end{tabular}

LN: Lymph node; VC: vincristine and cyclophosphamide; CCRT: concurrent chemoradiotherapy; 3DRT: three-dimensional conformal RT; IMRT: intensity-modulated radiation therapy; VMAT: volumetric-modulated arc therapy; Tomo: tomotherapy. *According to the Intergroup Rhabdomyosarcoma Study Group $(15,16)$; \#according to the Children's Oncology Group (17-19).

than 19 weeks, and 14 patients received RT for residual disease or involved lymph nodes. However, the 3-year DFS and OS were $30 \%$ and $45 \%$, respectively, considering all 20 patients. The 3-year OS rate for those with localized disease was higher than that for metastatic disease $(56.3 \%$ versus $0 \% ; p=0.089)$.

From the retrospective study conducted at the MD Anderson Cancer Center from 1957 through 2003, the median OS for patients with nonmetastatic disease was 45.6 months, and 16.8 months for those with metastatic disease (20). In their study, approximately $73 \%$ of patients received at least bimodality treatment (20). The improved median OS of the patients with localized RMS seen in our study may result from the fact that a majority of our patients were treated with VAC-based chemotherapy, intensive medical 

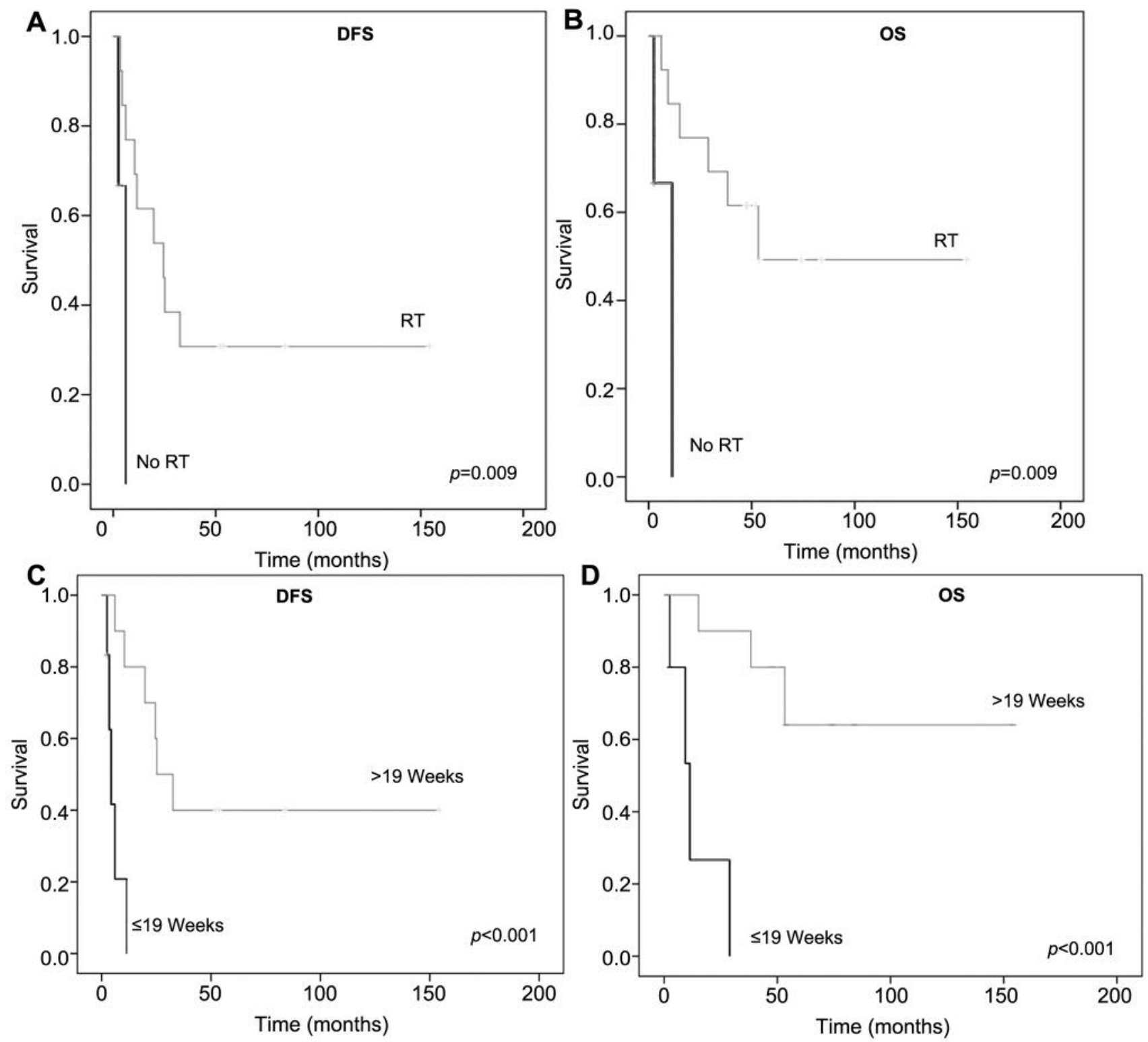

Figure 4. The disease-free $(D F S)(A, C)$ and overall $(O S)(B, D)$ survival outcomes of patients with localized rhabdomyosarcoma according to receipt of radiotherapy $(R T)(A, B)$ and by duration of chemotherapy administration $(C, D)$.

care, and precise RT dose-volume metrics. However, when compared to pediatric patients, the survival of our adult patients with RMS was still poor. The IRS-IV reported that 3 -year OS was $86 \%$ in pediatric patients with non-metastatic RMS (6). In addition, a recent published study from our Institution showed that the 5-year OS rate was $54.7 \%$ for pediatric patients under 18 years old (12).

Much of the published literature from single- or multipleinstitution series has presented similar results of inferior outcome in adult RMS (summarized in Table IV) (3, 8, 9, 20-24, 25, 26). When compared with other series, which reported regional lymph node metastasis rates ranging from $14 \%$ to $46 \%$ and unfavorable sites in approximately $53 \%$ at initial presentation $(21,22,24)$, our study found a higher rate of both initial lymph node involvement $(50 \%)$ and unfavorable sites (75\%). This may explain why our patients had lower 3-year DFS and OS. However, after incorporating multidisciplinary team care after 2010, the 3-year OS for our patients improved. Our colleagues also previously reported that a multidisciplinary team approach improved event-free survival in patients with high-risk neuroblastoma (27). These findings indicate that the incorporation of a 
Table IV. Published cohort studies of adult rhabdomyosarcoma.

\begin{tabular}{|c|c|c|c|c|c|c|c|c|}
\hline \multirow[b]{2}{*}{ Author (Ref) } & \multirow[b]{2}{*}{ Source } & \multirow[b]{2}{*}{$\begin{array}{c}\text { No. of } \\
\text { patients }\end{array}$} & \multirow[b]{2}{*}{ Time } & \multirow[b]{2}{*}{$\begin{array}{l}\text { Median age } \\
\text { (range), years }\end{array}$} & \multicolumn{2}{|c|}{ 5-Year OS } & \multicolumn{2}{|c|}{ Overall OS } \\
\hline & & & & & $\begin{array}{c}\text { All } \\
\text { patients }\end{array}$ & $\mathrm{M}+$ & M- & $\mathrm{M}+$ \\
\hline Sultan et al. (3) & SEER database & 1071 & $1973-2005$ & $>19$ years & $27 \%$ & $33 \%$ & $47 \%$ & \\
\hline Bompas et al. (8) & France & 157 & $1980-2010$ & $37(18-86)$ & $31 \%$ & $46 \%$ & $43 \%$ & $5 \%$ \\
\hline Hawkins et al. (9) & MSKCC & 84 & 1982-1999 & $23(16-76)$ & $35 \%$ & $44 \%$ & & \\
\hline Dumont et al. (20) & MSKCC & 239 & $1957-2003$ & $10-102(19)$ & & $32 \%$ & $44.1 \%$ & $18 \%$ \\
\hline Esnaola et al. (21) & $\begin{array}{c}\text { Brigham \& Women's } \\
\text { Hospital }\end{array}$ & 39 & $1973-1996$ & $26(16-82)$ & $31 \%$ & $33 \%$ & & \\
\hline Little et al. (22) & MDACC & 82 & $1960-1998$ & $27(17-84)$ & - & - & $44 \%$ & - \\
\hline Ferrari et al. (23) & Milan & 171 & $1975-2001$ & $27(19-83)$ & $39.6 \%$ & $18 \%$ & & $4.3 \%$ \\
\hline Gerber et al. (24) & MDACC & 148 & $1990-2011$ & $27(19-83)$ & $34 \%$ & $32 \%$ & $45 \%$ & \\
\hline Elsebaie et al. (25) (M-) & Database search & 553 & $\begin{array}{l}\text { Search on } \\
2015 / 1 / 15\end{array}$ & $30(16-87)$ & - & - & $52.7 \%$ & - \\
\hline $\begin{array}{l}\text { Noujaim et al. (26) } \\
\text { (pleomorphic) }\end{array}$ & $\begin{array}{l}\text { UK, Switzerland, } \\
\text { Germany }\end{array}$ & 49 & $1995-2014$ & $72(28-93)$ & & $29 \%$ & $31.2 \%$ & $0 \%$ \\
\hline Present study & NTUH, Taiwan & 20 & 2004-2015 & & $45 \%$ (3-years) & $20 \%$ & $56.25 \%$ (3-years) & $0 \%$ \\
\hline
\end{tabular}

N: Number; OS: overall survival; M+: metastatic disease; M-: non-metastatic; MSKCC: Memorial Sloan Kettering Cancer Center; MDACC: MD Anderson Cancer Center; NTUH: National Taiwan University Hospital.

multidisciplinary team approach in adult RMS may improve local control and improve OS.

A possible reason for lower survival in adult RMS is that the most common histological subtype in adults (pleomorphic) is not as responsive to chemotherapy as the embryonal or alveolar subtypes $(8,21,25,26)$. Another possibility is that the frequency of the pleomorphic subtype increases with advancing age and stage (9). In our cohort, the pleomorphic subtype accounted for nine out of $20(45 \%)$ patients, and seven $(77.8 \%)$ of these died. In a larger study conducted by the French Sarcoma Group, Bompas et al. reported that $44 \%$ of 449 patients had adult-type P-RMS (pleomorphic, spindle cell RMS, not otherwise specified), and a median OS of 16 months (8). This study also showed that RT significantly improved OS for patients with localized adult RMS (8), similar to our study. In addition to the use of RT in localized RMS, previous studies have suggested that longer duration of chemotherapy may have an impact by providing an improved survival benefit (28, 29). Most patients in our series undergoing chemotherapy for 19 weeks or less died, while almost $90 \%$ of patients who received chemotherapy for more than 19 weeks survived more than 3 years. Bisogno et al. from the European Paediatric Soft Tissue Sarcoma Study Group also demonstrated a better DFS in the standard and maintenance therapy group than the standard therapy group, indicating the importance of maintenance chemotherapy in high-risk non-metastatic RMS (29).

Despite the retrospective design and small sample size, we have presented the first single-institution series of adult RMS in Taiwan, and demonstrated that adult RMS is much different histologically (mainly pleomorphic subtype), and behaves more aggressively compared to pediatric RMS. In addition to IRSG stage, risk level, and histological subtype, our data indicate that adult patients with localized RMS may achieve improved survival when they receive concurrent chemotherapy and RT, and longer duration of systemic chemotherapy (>19 weeks). Future studies with larger patient cohorts may validate the prognostic factors we identified, warranting further investigation of novel multimodality treatment strategies to improve outcomes of adult RMS.

\section{Conflicts of Interest}

The Authors have no conflicts of interest to declare in regard to this study.

\section{Authors' Contributions}

YTL collected the data, conducted all statistical analyses and wrote the article; CWW and RLH contributed data, and SHK conceived, designed the work and revised the article. All authors reviewed and approved the final article.

\section{Acknowledgements}

This study was supported by research grants MOST 107-2314-B002-217-MY3 from the Ministry of Science and Technology, Taiwan, NTUH 108-S4143 from National Taiwan University Hospital, Taiwan, and MOHW 107-TDU-B-211-114017 from the Ministry of Health and Welfare, Taiwan. The funding sources had no involvement in the study design, collection, analysis and interpretation of data, writing of the report, and the decision to submit the article for publication. 


\section{References}

1 Crist WM and Kun LE: Common solid tumors of childhood. N Engl J Med 324: 461-471, 1991. PMID: 1988832. DOI: 10.1056/NEJM199102143240706.

2 Liu YL, Lo WC, Chiang CJ, Yang YW, Lu MY, Hsu WM, Ho WL, Li MJ, Miser JS, Lin DT and Lai MS: Incidence of cancer in children aged 0-14 years in Taiwan, 1996-2010. Cancer Epidemiol 39: 21-28, 2015. PMID: 25599927. DOI: 10.1016/ j.canep.2014.11.010.

3 Sultan I, Qaddoumi I, Yaser S, Rodriguez-Galindo C and Ferrari A: Comparing adult and pediatric rhabdomyosarcoma in the surveillance, epidemiology and end results program, 1973 to 2005: An analysis of 2,600 patients. J Clin Oncol 27: 3391-3397, 2009. PMID: 19398574. DOI: 10.1200/JCO.2008.19.7483.

4 Maurer HM, Moon T, Donaldson M, Fernandez C, Gehan EA, Hammond D, Hays DM, Lawrence W Jr., Newton W, Ragab A, Raney B, Soule EH, Sutow WW and Tefft M: The Intergroup Rhabdomyosarcoma Study. A preliminary report. Cancer 40: 2015-2026, 1977. PMID: 336175.

5 Crist W, Gehan EA, Ragab AH, Dickman PS, Donaldson SS, Fryer C, Hammond D, Hays DM, Herrmann J and Heyn R: The Third Intergroup Rhabdomyosarcoma Study. J Clin Oncol 13: 610-630, 1995. PMID: 7884423. DOI: 10.1200/JCO. 1995.13.3.610.

6 Crist WM, Anderson JR, Meza JL, Fryer C, Raney RB, Ruymann FB, Breneman J, Qualman SJ, Wiener E, Wharam M, Lobe T, Webber B, Maurer HM and Donaldson SS: Intergroup Rhabdomyosarcoma Study-IV: Results for patients with nonmetastatic disease. J Clin Oncol 19: 3091-3102, 2001. PMID: 11408506. DOI: 10.1200/JCO.2001.19.12.3091.

7 van der Graaf WT, Orbach D, Judson IR and Ferrari A: Softtissue sarcomas in adolescents and young adults: A comparison with their paediatric and adult counterparts. Lancet Oncol 18: e166-e175, 2017. PMID: 28271871. DOI: 10.1016/S14702045(17)30099-2.

8 Bompas E, Campion L, Italiano A, Le Cesne A, Chevreau C, Isambert N, Toulmonde M, Mir O, Ray-Coquard I, PipernoNeumann S, Saada-Bouzid E, Rios M, Kurtz JE, Delcambre C, Dubray-Longeras P, Duffaud F, Karanian M, Le Loarer F, Soulié P, Penel N and Blay JY: Outcome of 449 adult patients with rhabdomyosarcoma: an observational ambispective nationwide study. Cancer Med 7: 4023-4035, 2018. PMID: 29956493. DOI: 10.1002/cam4.1374.

9 Hawkins WG, Hoos A, Antonescu CR, Urist MJ, Leung DH, Gold JS, Woodruff JM, Lewis JJ and Brennan MF: Clinicopathologic analysis of patients with adult rhabdomyosarcoma. Cancer 91: 794-803, 2001. PMID: 11241248.

10 Raney RB Jr, Tefft M, Maurer HM, Ragab AH, Hays DM, Soule $\mathrm{EH}$, Foulkes MA and Gehan EA: Disease patterns and survival rate in children with metastatic soft-tissue sarcoma: A report from the Intergroup Rhabdomyosarcoma Study (IRS)-I. Cancer 62: 1257-1266, 1988. PMID: 2843274.

11 Egas-Bejar D and Huh WW: Rhabdomyosarcoma in adolescent and young adult patients: Current perspectives. Adolesc Health Med Ther 5: 115-125, 2014. PMID: 24966711. DOI: 10.2147/AHMT.S44582.

12 Chou SW, Chang HH, Lu MY, Yang YL, Lin DT, Lin KH and Jou ST: Clinical outcomes of pediatric patients with newly diagnosed rhabdomyosarcoma treated by two consecutive protocols - A single-institution report in Taiwan. J Formos Med Assoc 118: 332340, 2019. PMID: 29903549. DOI: 10.1016/j.jfma.2018.05.015.
13 Granowetter L, Womer R, Devidas M, Krailo M, Wang C, Bernstein M, Marina N, Leavey P, Gebhardt M, Healey J, Shamberger RC, Goorin A, Miser J, Meyer J, Arndt CA, Sailer S, Marcus K, Perlman E, Dickman P and Grier HE: Doseintensified compared with standard chemotherapy for nonmetastatic Ewing sarcoma family of tumors: A Children's Oncology Group Study. J Clin Oncol 27: 2536-2541, 2009. PMID: 19349548. DOI: 10.1200/JCO.2008.19.1478.

14 Weigel B, Lyden E, Anderson JR, Galster A, Arndt AC, Michalski J, Hawkins DS and Meyer WH: Early results from Children's Oncology Group (COG) ARST0431: Intensive multidrug therapy for patients with metastatic rhabdomyosarcoma (RMS). J Clin Oncol 28: 9503-9503, 2010. DOI: $10.1200 / J C O .2010 .28 .15 \_s u p p 1.9503$.

15 Lawrence W Jr., Anderson JR, Gehan EA and Maurer H: Pretreatment TNM staging of childhood rhabdomyosarcoma: A report of the Intergroup Rhabdomyosarcoma Study Group. Children's Cancer Study Group. Pediatric Oncology Group. Cancer 80: 1165-1170, 1997. PMID: 9305719.

16 Raney RB, Maurer HM, Anderson JR, Andrassy RJ, Donaldson SS, Qualman SJ, Wharam MD, Wiener ES, Crist WM and The Intergroup Rhabdomyosarcoma Study Group (IRSG): Major lessons from the IRS-I through IRS-IV studies as background for the current IRS-V treatment protocols. Sarcoma 5: 9-15, 2001. PMID: 18521303. DOI: 10.1080/13577140120048890.

17 Breneman JC, Lyden E, Pappo AS, Link MP, Anderson JR, Parham DM, Qualman SJ, Wharam MD, Donaldson SS, Maurer $\mathrm{HM}$, Meyer WH, Baker KS, Paidas $\mathrm{CN}$ and Crist WM: Prognostic factors and clinical outcomes in children and adolescents with metastatic rhabdomyosarcoma - A report from the Intergroup Rhabdomyosarcoma Study IV. J Clin Oncol 21: 78-84, 2003. PMID: 12506174. DOI: 10.1200/JCO.2003.06.129.

18 Meza JL, Anderson J, Pappo AS, Meyer WH and Children's Oncology Group: Analysis of prognostic factors in patients with nonmetastatic rhabdomyosarcoma treated on Intergroup Rhabdomyosarcoma Studies III and IV: The Children's Oncology Group. J Clin Oncol 24: 3844-3851, 2006. PMID: 16921036. DOI: 10.1200/JCO.2005.05.3801.

19 Hawkins DS, Spunt SL and Skapek SX: Children's Oncology Group's 2013 blueprint for research: Soft tissue sarcomas. Pediatr Blood Cancer 60: 1001-1008, 2013. PMID: 23255356. DOI: $10.1002 / \mathrm{pbc} .24435$.

20 Dumont SN, Araujo DM, Munsell MF, Salganick JA, Dumont AG, Raymond KA, Linassier C, Patel S, Benjamin RS and Trent JC: Management and outcome of 239 adolescent and adult rhabdomyosarcoma patients. Cancer Medicine 2: 553-563, 2013. PMID: 24156028. DOI: 10.1002/cam4.92.

21 Esnaola NF, Rubin BP, Baldini EH, Vasudevan N, Demetri GD, Fletcher CD and Singer S: Response to chemotherapy and predictors of survival in adult rhabdomyosarcoma. Ann Surg 234: 215-223, 2001. PMID: 11505068.

22 Little DJ, Ballo MT, Zagars GK, Pisters PW, Patel SR, El-Naggar AK, Garden AS and Benjamin RS: Adult rhabdomyosarcoma: Outcome following multimodality treatment. Cancer 95: 377-388, 2002. PMID: 12124838. DOI: 10.1002/cncr.10669.

23 Ferrari A, Dileo P, Casanova M, Bertulli R, Meazza C, Gandola L, Navarria P, Collini P, Gronchi A, Olmi P, Fossati-Bellani F and Casali PG: Rhabdomyosarcoma in adults. A retrospective analysis of 171 patients treated at a single institution. Cancer 98: 571-580, 2003. PMID: 12879475. DOI: 10.1002/cncr.11550. 
24 Gerber NK, Wexler LH, Singer S, Alektiar KM, Keohan ML, Shi W, Zhang Z and Wolden S: Adult rhabdomyosarcoma survival improved with treatment on multimodality protocols. Int J Radiat Oncol Biol Phys 86: 58-63, 2013. PMID: 23414767. DOI: $10.1016 /$ j.ijrobp.2012.12.016.

25 Elsebaie MAT, Amgad M, Elkashash A, Elgebaly AS, Ashal GGEL, Shash E and Elsayed Z: Management of low- and intermediate-risk adult rhabdomyosarcoma: A pooled survival analysis of 553 patients. Sci Rep 8: 9337, 2018. PMID: 30046147. DOI: 10.1038/s41598-018-29513-4.

26 Noujaim J, Thway K, Jones RL, Miah A, Khabra K, Langer R, Kasper B, Judson I, Benson C and Kollàr A: Adult pleomorphic rhabdomyosarcoma: A multicentre retrospective study. Anticancer Res 35: 6213-6217, 2015. PMID: 26504053.

27. Chang HH, Liu YL, Lu MY, Jou ST, Yang YL, Lin DT, Lin KH, Tzen KY, Yen RF, Lu CC, Liu CJ, Peng SS, Jeng YM, Huang SF, Lee H, Juan HF, Huang MC, Liao YF, Lee YL and Hsu WM: A multidisciplinary team care approach improves outcomes in high-risk pediatric neuroblastoma patients. Oncotarget 8: 43604372, 2017. PMID: 27966455. DOI: 10.18632/oncotarget.13874.
28 Oberlin O, Rey A, Brown KL, Bisogno G, Koscielniak E, Stevens MC, Hawkins DS, Meyer WH, La TH, Carli M and Anderson JR: Prognostic factors for outcome in localized extremity rhabdomyosarcoma. Pooled analysis from four international cooperative groups. Pediatr Blood Cancer Dec 62: 2125-2131, 2015. PMID: 26257045. DOI: 10.1002/pbc.25684.

29 Bisogno G, Luca De Salvo G, Bergeron C, Jenney M, H.M. Merks J, Minard-Colin V, Orbach D, Glosli H, Chisholm J, Casanova M, Gallego Melcon S and Ferrari A: Maintenance lowdose chemotherapy in patients with high-risk (HR) rhabdomyosarcoma (RMS): A report from the European Paediatric Soft Tissue Sarcoma Study Group (EpSSG) 36: LBA2-LBA2, 2018. DOI: 10.1200/JCO.2018.36.18_suppl.LBA2.

Received January 21, 2019

Revised February 2, 2019

Accepted February 7, 2019 